\section{No. 4772 April 15, 1961}

been in engineering, followed by education and agriculture. Of 170,000 with engineering degrees, 90 per cent have received them since 1949, while of 38,000 graduates in the natural sciences, two-thirds are Communist trained. Great inefficiency appears to exist in the estimates of future man-power requirements and in placing graduates. Most of the serious scientific work is being done in the Chinese Academy of Sciences, which in 1958 had almost 6,000 research workers (almost 75 per cent being assistants, trainees or technicians), and its affiliated institutes; even here scientific research was integrated with production. In 1958 , the 650 research institutes in science and technology employed a staff of 82,100 , of whom 18,100 were research and technical workers, 14,700 in industry and communications, 1,200 in agriculture and related fields and 2,200 in medical science and public health, but it cannot be assumed that all have completed professional training. Many engineering graduates are, in fact, little more than skilled technicians and many science graduates advanced laboratory technicians. China undoubedly possesses a limited number of first-rate scientists, but, at least in the immediate future, her achievements in science, as in overall economic growth, will depend on how much help is obtained from the U.S.S.R. More and more persons will graduate from the advanced institutions now established to train scientists and technologists, but their function must be problematic while China continues the policy of adapting present knowledge to immediate needs rather than sponsoring creative research.

\title{
TREATMENT OF RINGWORM BY GRISEOFULVIN
}

$\mathrm{T}$ INEA CAPITIS (ringworm of the scalp) is a dermatomycosis mainly affecting groups of children of school age. Although not serious, the disease is conspicuous, and affects the morale of children, keeping them from school and from participation in normal childhood activities. The bacterial complications to which it may give rise are sometimes serious.

The disease is carried home from school or from a group of playmates, and a reservoir of infection is then established among adults. In some communities in Israel, the proportion of adults suffering from ringworm is higher among women than among men. On the other hand, in Moslem communities it appears to be the men who maintain the disease and run the risk of serious infection, because of their custom of shaving their heads, which is frequently done without due attention to hygiene. Moslem women are protected by the care they give their hair.

Ringworm is particularly widespread in communities where life is organized around the family or the tribe or where people live together in crowded conditions. Some persons contract ringworm more easily than others exposed to the same risk, and the disease is more frequent among children suffering from protein deficiency. In the (then) Belgian Congo, Vanbreusghem examined thousands of children and found that its prevalence varied between 5 and 40 per cent. It was higher in areas where serious protein deficiency was known to occur and kwashiorkor was present. The same applied to cases treated in hospital: in Bukavu, 89 per cent of the children suffering from kwashiorkor were infected with ringworm. At present it is impossible to say whether this arises from a lack of vitamin A accompanying protein deficiency, a change in the sebaceous secretion of the scalp, or some abzormality of the skin or hair related to kwashiorkor and favouring the development of fungi.

In North Africa, in some parts of Central Africa, in the Eastern Mediterranean basin, in certain parts of the United States where there is a high percentage of Negroes, and in various parts of eastern Europe, ringworm may affect 30-40 per cent of the children. The health authorities of several countries have decided to attack this problem and the World Health Organization is giving assistance to the Province of Syria, the United Arab Republic and to Tunisia. In Yugoslavia, where a systematic campaign against ringworm is under way, the Organization has assisted a demonstration project of mass griseofulvin treatment, directed by Prof. E. I. Grin. The campaign being carried out and a general survey on ringworm and its treatment are outlined in a recent issue of the $W H O$ Chronicle*.

The dermatophytic fungi (Trichophyton, Micro. sporum) live and multiply at the expense of the keratin they digest; as a result, the growth of the hair is impaired and it falls out, leaving bald patches.

The treatment used until quite recently consisted in desquamation of the parts affected so as to remove the diseased keratin, and the disinfection of the patches in order to prevent contamination of newly formed keratin. For this purpose, fungicidal ointments and pomades, and even X-ray therapy, which causes depilation, were employed. None of these methods gave reliable and permanent results. It was necessary to find a new treatment, acting internally instead of externally, that would enable keratin-producing cells to resist the fungus, and continue to resist it after they had become keratinized.

The discovery of griseofulvin provided an antibiotic satisfying these requirements. Isolated in 1939 from Penicillium griseofulvum, then from several other species of Penicillium, the antibiotic was identified chemically and used in horticulture against certain fungal plant pathogens. Its powerful fungistatic action attracted the attention of dermatologists, and, starting in 1958, investigations were carried out on its use in the treatment of certain human and animal dermatomycoses. The antibiotic gave better results than any form of treatment previously applied. It was more active when administered orally than parenterally, was not found in the serum of treated subjects, but, on the other hand, could be detected in their hair. In therapeutic doses it did not have any harmful or irreversible side effects. As a result of these outstanding properties it was decided to use it for mass treatment.

Following mass immigrations from highly endemic areas after 1948, ringworm, which had been almost unknown in Israel, again developed into a public health problem. The number of new cases reached 4,000-6,000 per annum. The good results obtained elsewhere with griseofulvin encouraged Israeli health authorities to adopt it for a mass campaign, after confirming its effectiveness and harmlessness in a

* WHO Chronicle, 15, No. 2; February 1961. 
preliminary trial with a group of women and children in hospital at Tel-Hashomer.

Those most seriously affected are children aged 5-14 years. Although in most cases the condition clears up spontaneously at puberty, some victims bear the marks of the disease throughout their lives.

Trichophyton violaceum is the most widespread parasite ; favus caused by $T$. schoenleini is also encountered. In the Arab village where the campaign was carried out there were $441 T$. violaceum and 5 $T$. schoenleini cases. Griseofulvin was administered in single doses of $25 / 30 \mathrm{mgm}$. $/ \mathrm{kgm}$. of body weight a day. At the end of three weeks there was a marked improvement in most cases. After eight weeks, 99 per cent of the $T$. violaceum infections and 60 per cent of the $T$. schoenleini infections were cured. All cases were cured after treatment for ten weeks. Twenty-five cases which were followed up after 2-6 months did not suffer any relapse.

\section{DYNAMICS AND ENERGETICS OF SWIMMING IN WATER-BEETLES}

\section{BY DR. WERNER NACHTIGALL}

Strahlenbiologisches Institut der Universität, Bavariaring 19, München

$\mathrm{K}^{\mathrm{n}}$ INEMATIC and dynamic measurements ${ }^{1}$ were carried out on Acilius sulcatus L. (Dytiscidae). The resistance coefficient $c_{w}$ of the Acilius torso, as a criterion of its flow adaptation, amounts to $0 \cdot 23$ for a Reynolds' number, $R_{e}$ of $5 \times 10^{3}$ to $8 \times 10^{3}$. Consequently, Acilius produces only $5 \cdot 75$ times as much resistance for a given velocity as a drop-shaped body of best adaptation, having a comparable frontal area, but only half as much as a corresponding ball. This very favourable value results from the dorsoventral flattening of the body, the greatest height of which lies in the front third and the greatest width in the rear third of the body, where the epipleura are pulled out so that the borders are sharp. There is no essential difference in velocity between dorsal and ventral flow, and there is no enlargement of the resistance coefficient by a smaller $R_{e}$ as a result of the preformed places of vortex separations (Fig. 1). The body ends in a half-round edge; this hinders the vorticity of the plane separating dorsal and ventral flow. Measurements prove the hydrodynamic efficiency of this body-form ; the resistance rises to about 120 per cent if the flow comes from behind, and to about 122 per cent if the edge is cut off. This body. form also possesses excellent swimming stability.

The single propulsion factor is the part of rudder. stroke force consumed by metapodial swinging that lies in the direction of movement, the forward drive. With each rudder-stroke, the forward drive impulse, $I_{R}$, that is, the time integral of the propulsive force during the rudder stroking, is reduced by the counterdrive impulse, $I_{V}$, which results from the forward pulling of the metapodials. The fraction of the total impulse available for propulsion, $\eta=I_{R} /$ $\left(I_{R}+I_{V}\right)$, is the efficiency of underwater swinging as a propulsive factor. It can equal 1.0 in an ideal situation and it can be determined graphically in a complicated way for the stationary $\left(\eta_{1}\right)$ and freely swimming $\left(\eta_{2}\right)$ animal as follows : slow-swimming movement, $\eta_{1}=0.84, \eta_{2}=0.72$; medium-swimming movement, $\eta_{1}=0.87, \eta_{2}=0.78$; fastest-swimming, $\eta_{1}=0.91, \eta_{2}=0.81$. The $\eta$ values for freely swimming animals are somewhat lower than for stationary ones, since the pulling forward of the metapodials happens in water which is moving in relation to the swimming animal. The faster the animal swims, the better is the efficiency; the greater the applied power, the better it is utilized. The levels of efficiency are surprisingly high with an average of 80 per cent. This is explained by the morphological and kinematic peculiarities of the metapodials.
In the rudder-stroke the surface of the leg, $F$, and the stroking speed, $v$, are large. Therefore, the induced resistance $W$, proportional to $F v^{2}$, is very high. The leg stands with broad sides and with swimming hairs spread perpendicular to the direction of stroking; $v$ is usefully maximal, when the leg is perpendicular to the median. During the 'partial thrust time' the expended force is changed in propulsion from 98 per cent to 100 per cent, and further to 70 per cent. The resulting harmful side-force amounts to a maximum of only 23 per cent of the forward drive.

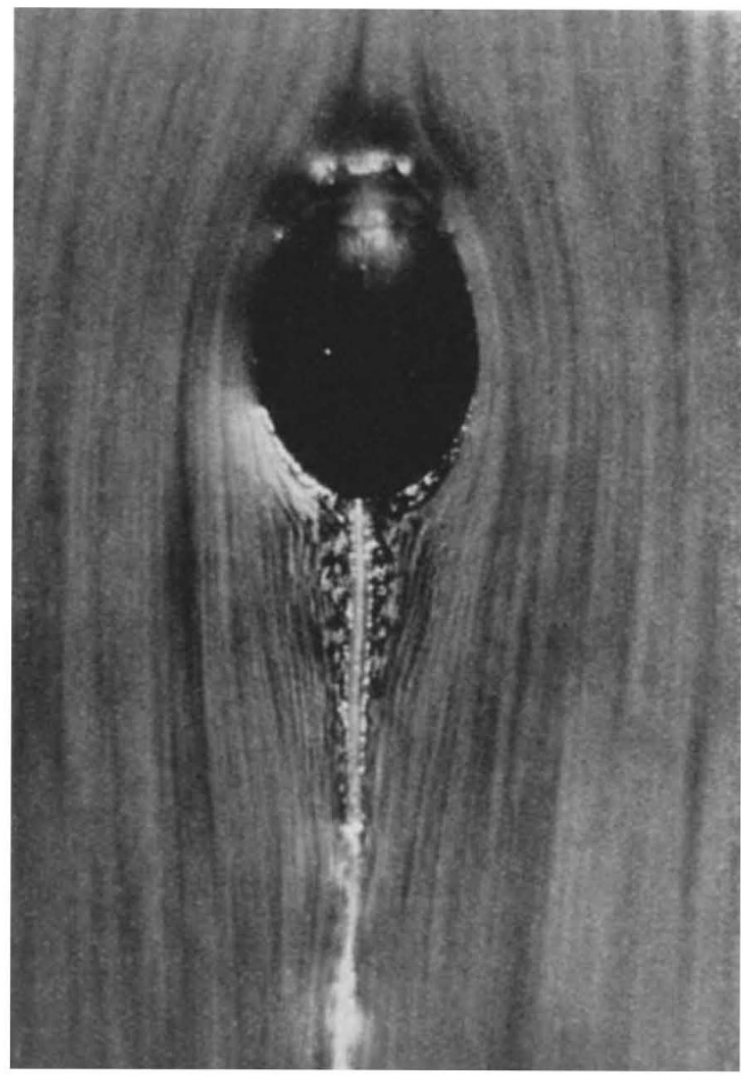

Fig. 1. Acilius sulcatus, L. Flow around the frontal area ; The laminar an associated reference system at $v=35 \mathrm{~cm}$./ $\mathrm{sec}$. the laminar flow changes at the widest position of the torso into $\left(R_{e}=6,000\right)$ 